\title{
Stepping Up the English Speaking Proficiency of Hospitality Students through Video Blogs (Vlogs)
}

\author{
Siska Amelia Maldin, Syailendra Reza, and Irwansyah Rezeki \\ Batam Tourism Polytechnic \\ (BTP) \\ Batam, Indonesia \\ siskamaldin@btp.ac.id/siskamaldin982@gmail.com
}

\begin{abstract}
Nowadays, there is a greater trend in EFL teaching where technology is integrated in the classroom to improve communicative environment during language learning which trigger English instructors who work in ESP language teaching to create a teaching technique that can improve the communication skills of their students. Hence, the idea of using Vlog in classroom as one of task-based language teaching concept is proposed to help students to practice English independently outside of classroom, particularly for speaking skill that they find difficult to learn. Thus, the aim of this paper is to show how Vlog, a fusion of video and blog,is used in EFL teaching and learning in classroom to develop students' spoken skills and public communication. This paper also intended to discuss how teachers and students can very easily use Vlog by integrating smartphone, camera and computer mechanism. The samples of this research were students of Culinary and Food \& Beverage Management of Batam Tourism Polytechnic. The research was a qualitative study where the data obtained from case analysis on strategies implemented by researcher to integrate Vlog in teaching and learning process.
\end{abstract}

Keywords: Teaching English, Communication skills, Vlog, TeacherStudent Collaboration

\section{INTRODUCTION}

The goals of teaching English for specific purpose for Tourism and Hospitality students in Indonesia are not only for introducing English in academic level, but for gaining students' interest to place the four notions of skills (listening, speaking, reading, and writing) in English language as a part of individual practical use in everyday life. This becomes a massive challenge for ESP lecturers, and teachers to build interest and unleash students' motivation for making use of English in daily life activity.

Unfortunately, there are numerous resistances face by teachers in reaching the goals such aslack of materials supplies and teaching strategies that may provide the need of students to learn English in the classroom. This is proven by an observation conducted in Culinary and Food Beverage Management students at the $2^{\text {nd }}$ semester at Batam Tourism Polytechnic who were taken English for Hospitality II subject. Although the goal of the process where to encourage students to use English for their daily interaction and to support their performance at the workplace or when following internship program or training, the gap is discovered from the high level of students' anxiety while asking to perform English. Thus, it can be perceived that the resistance of encouraging students to practice English is generally affected by students' low motivation and awareness in encouraging themselves to practice. As a result, they tend to alleviate even refuse to participate in the classroom. Hammer in Sad (2008) says that those uncooperative and unmotivated students are a serious problem who can easily disrupt the process. Other resistance is every day class activities like drilling, that also contribute to lower motivations.

Referring to the resistances above, a direct solution is needed based on the current students' need and correlation of the sphere condition of life mobility and grow of technology nowadays. As these days, it seems English for Specific Purpose teaching and learning can be set up into a project-based learning that based on instructional strategies approach which is set up to design particular activities or project to gain students capability and creativity. It can be done through creating a simple film documentary, which called Vlog as one of the way to encourage students to practice. By integrating students' produced Vlog project in ESP teaching, it is hoped that students are going to get a great access of independent practice while they were asked to learn through creating a project.

Therefore, this study attempts to explain the analysis on sequence of teaching strategies that teachers or instructors have done before asking the students to create the Vlog and the students' attitude on the implementation of the project task. Since the project based tasks are not generally used in traditional paper-based classrooms, the 
students' exposure and attitude towards creating Vlog would initiate them to improve their English communication and capability in their second language learning process. This paper further discusses how Vlog is helpful to learners improve their societal influence with their fellow students and self-analysis their personal capability by the feedback on the Vlog.

A. What is Vlog?

\section{THEORETICAL REVIEW}

Vlog is a fusion of video and blog. Vlog are done through a Smartphone or computer- connected with a video camera and internet connection. It can allow students to record their speech and upload them to the Vlogs. Smartphone with VLC is an open source that can be used unreservedly to play video clippings by using VideoLAN. When Vlogging students can cobine the video performance with music, film clips, images and written messages in order to make the video becomes interesting. Personal computer users can use Windows Movie Maker and Android or I-phone users can edit videos on their mobile before they upload the files. After completing the process of uploading videos, students can share their files with their friends, classmates and the instructor to receive feedback about the project. This procedure can be significantly done via internet, but in the case of non-availability of internet, USB memory cards can be used. With the aid of internet, extensive and relevant websites can be utilized to upload and screen videos on the public forum.

Nowadays, students are technology addicted and update their knowledge about technology. Then, Youtube.com is one of the most famous online video screening sites and students are fairly connected with it. Creating an account and hosting a video on Youtube is rather an easy task for students. The only drawback is lack of privacy as anybody can view it without any restriction, but in Vlog the user can make the videos private by creating an URL (Uniform Resource Locator). Moreover, Facebook is another important video uploading application. Instructor can create an account for her/his class and only the members can view the contents. Such official face book can completely relate to academic interaction, so that a line can be drawn between students and teacher. Facebook and YouTube can be easily accessible by students when they have internet connectivity to their computer.

Smartphone applications like Whatsapp, Hiker, Roposo can be used but the limit of recording is restricted as the memory of the phone cannot store too many lengthy videos. But a small video can be shared on the group. Another Vlog hosting option is Dropbox.com. Dropbox allows users to share a minimum of 5 GB (Gigabytes) which can comprise any word document, PDF, zipped files, audio files, video files with others. Students can upload the videos or files after editing them that can be viewed by the teacher or only by the approved class mates.

B. What is correlation between Vlog (video production) with instructional strategy or task based?

Furthermore, the aspect of video production can be interpreted as an instructional strategy for teaching content, not a set of tools and processes to be mastered as isolated skills. Instructional strategies are what instructors do to facilitate student learning (Dabbagh\&Bannan-Ritland, 2005). As Jonassen, Grabinger, and Harris (1991) stated, instructional strategies are "the plans and techniques that the instructor/instructional designer uses to engage the learner and facilitate learning" (p. 34) and represent "a plan, method or series of activities, aimed at obtaining a specific goal" (p. 31). Thus, for example, video production as an instructional strategy might link video essays with Civil War concepts or documentaries with the study of historical and current immigration issues or marketing videos with promoting a book, an invention, or an environmental cleanup. In this application of video production, the media are not studied formally, but the analysis of media text and the creation of media messages are emphasized as components of course work in the traditional disciplines.It can also be perceived that integrating instructional strategies approach in the classroom, will carry great potential for students to gain exposure to media analysis and production activities while simultaneously mastering the complexities of disciplinary knowledge (Hobbs, 1998). As Hofer and Swan (2005) wrote, "The engaging and flexible nature of digital moviemaking projects offers great potential to ground the use of technology in discipline-specific content and processes" (p. 108).

Focusing on the ESP classroom, recent developments in the education literature suggest that students benefit from constructing their own understanding of concepts and information in the video creation might generate their creativity as long as it relates with their major of study or future working fields. On the other hand, rapid changes in technology cause some educators to immerse themselves in the new technology and look for opportunities to implement the technology in the classroom. As Hofer and Swan (2005) point out, this is like a "hammer in search of a nail," which means a seemingly inefficient strategy for creating new pedagogy.

Moreover, Gehringer and Miller (2009), recognize that active learning exercises need not be created solely by the instructor and that students may benefit in multiple ways by giving them an opportunity to construct their own activities to master subject content. In the classroom experiments, the instructors witnessed several student groups utilizing digital media to create learning activities, specifically videos to explain complex subject content. Gehringer 
and Miller (2009) investigated whether students were more engaged with activities that the students helped create and they were able to demonstrate that student engagement clearly increased with student created learning activities

A. Setting and Participants

\section{METHOD}

The subject of this research was two classes of students, one from culinary management major and second from food and beverage management major at Batam Tourism Polytechnic. The project was made by students in the group of 5 to 7 students in each class with total 32 students (19 students from Culinary Management and 8 students from Food and Beverage Management) which was divided in 7 groups (5 groups from culinary management major and 2 groups from food and beverage management major). The subject of this research was two classes of students, one from culinary management major and second from food and beverage management major at Batam Tourism Polytechnic. The project was made by students in the group of 5 to 7 students in each class with total 32 students (19 students from Culinary Management and 8 students from Food and Beverage Management) which was divided in 7 groups ( 5 groups from culinary management major and 2 groups from food and beverage management major) .

B. Research methodology and procedures

The study was aqualitative study since whose purpose is to describe the status of a particular condition. Clearly, Cresswel, John W. (2003:22) states that qualitative approach generalizes the advantages of collecting open-ended questions, emerging approaches, text or image data to best understand a research problem. Second reason to choose this type of research design was based on the construing of the research questions. Based on the research questions, this research was designed to answer questions types of suggestion acts performed by instructors. By answering the questions, it can be perceived that it was amenable this type of research design because the later findings revealed the extent to which the current status of the study.

To be more specified, this research was purposed to explore the central phenomenon discovered from the implementation of strategies to the participants at this study. The study also sought explanation to how the strategies may contribute to the development of students English proficiency and motivation especially who those that taken English for Specific Purposes or in the vocational studies. This is not an intervention study, whether there might be an improvement on students' performance but overall is only to describe and present the status of particular study. It's only a study to present how the strategies are implemented and examine if it may contribute change on students attitude and motivation.

The data of this research were the teaching strategies that instructors tend to implement during the study and the students' attitude on the implementation of instructional strategy like a video project in their classroom. The steps to do the data collection and analysis are the researcher summarized and identified the strategies before preparing the students to do the video project. Next, the strategies were discussed to present the sequence of activities to show how the instructor or teacher facilitates the students on the project construction. Third, the students' attitudes were analyzed in order to see the increase on their motivation and awareness.

\section{DisCUSSION}

From the interaction in the classroom, it can be seen that the arrangement of strategies implementation were divided into four major stages; pre-production, production, editing, and sharing. The breakdowns of each stage can be seen as follows. On the pre-production stage, instructors and students were brainstorming the topic or idea to create Vlog. After finishing with brainstorming the ideas, instructors explained to students the explanation related to pre-preparation to create video like designing a planning and rubric about what will happen in the video, whowould do what like roles and editing, and know what they want from the project. Next, it will be continued to storyboarding/scripting where the students will sketch out scenes in the video project.

When they have already finished to sketch the scenes, instructor may asked the students to do independent task at home to do writing and scripting of their video content, including also the storyboard that consisted of the visuals and audio played on the video. Then, instructors may asked the students to do planning the place/backgrounds the video will be shot at, making sure timing when to record the video, and creating costumes. In this stage, instructors also need to remain the students to know their lines and use cue cards if needed. The explanation of this preproduction stage might be done in 30-45 minutes before regular studying process. It is also important to bear in mind that instructor should always monitor the progress of students work by asking them to make their progress rubric.

After the pre-production is done, instructor may assign the students to do a production stage, where they will be asked to shoot the visual based on their own scripting. Instructors can ask the students to do a shooting session depends on the class agreement, it was done from one to three weeks depends on the readiness of the students. Thus, 
the video project was set to be the final project for students which collected at the end of semester. Once the students has called finished to record the video, instructor asked the students to prepare for editing by using appropriate software like windows movie maker or viva video and sharing the video in the social media like Facebook and Youtube.

In order to observe students' attitude and perception on the video project above, the survey were given to culinary and food \& beverage management students to gather their perception toward the implementation of video project. The survey was conducted online by using www.surveymonkey.com. 10 statements were proposed to students about their perception on the video project (see appendix 1). The data can be seen in the Figure 1 below.

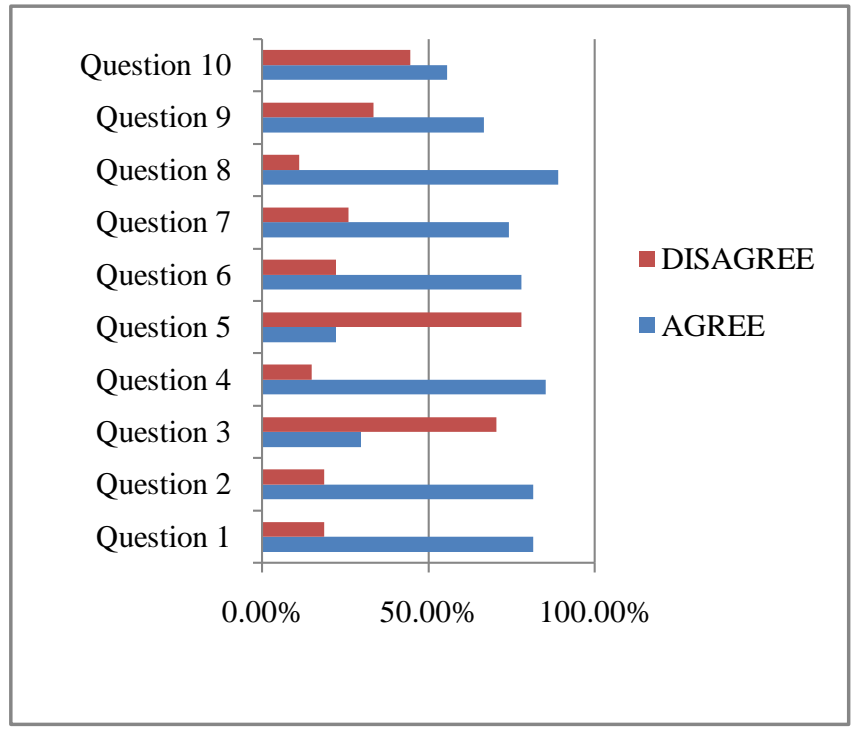

Fig. 1. Students' Response on the Implementation of Video Project

From the graphic above, it can be seen that majorly students were positively respond the implementation of video project. Fewer students were found reluctant with the implementation of video project in the classroom. Based on the question given to students, most of them agreed that video project is not hard to do and they can show their creativity in creating the video. Mostly students are positively responds to the making of the project video and they do not feel bored to create the video. From the previous graphic, it is also seen that only 1 to 2 students from each major who find difficult and hard to create project video. Probably, it is caused by less coordination and cooperation while creating the video not on the basis of their proficiency.

From the finding, there are several ideas can be discussed dealing with the making of project video for students. It is seen that the implementation of project were correlated with what Gehringer and Miller (2009) said that active learning exercises need not be created solely by the instructor and that students may benefit in multiple ways by giving them an opportunity to construct their own activities to master subject content. This aspect can be seen from the series of process that students and instructors conduct before the project begins and when it comes to editing, students may involve their creativity to create the video and it shares the positive and fun aspects of learning foreign language. Additionally, Vlog is also helpful to students as they can be motivated and encouraged to express their views on any topic freely but within a stipulated time. Time constraint will encourage them to do in a better and comparative way. Instructor can create interesting topics or relevant questions to make students speak about it within an allotted time.

Moreover, integrating instructional strategy like asking the students to create $V l o g$, is proven as what instructors do to facilitate student learning (Dabbagh\&Bannan-Ritland, 2005). In this case, instructors do not solely encourage students to expand only one English skill, like speaking, but also to motivate the students to develop another three skills like listening, reading and writing that were seen from the process before the project done. It is proved that integrating Vlog in vocational studies are beneficial as students may improve their capabilities by comprehending language that correlate with their major of study. Thus, it can be perceived that asking students to create Vlog may share several benefits as follow. First, students will retain what they learn because Vlog may help students to have more times to practice English to empower the four English skills. Second, Vlog promotes creativity in learning as students are engaged in the process and collaborate with other students to create an art. 
Third benefit is students are trained to practice the any aspects in planning, organizing, time management, cooperative learning, communication, technology skills, and problem solving. Fourth, creating Vlog may upgrade students to think at higher level which is seen from the process where students sew the information together in an organized way that forces students to think about the entire body of information. Fifth, as Vlog deals with editing and internet sharing, this might also increase students' capability in technological skills. Then, obviously Vlog creation is absolutely fun and interesting. In addition, a positive aspect of integrating Vlog was that the instructor and students were consistently spending more discussion together. This was especially useful and enabled students to practice their pronunciation, intonation, and body movements for the drama. Instructor feedback was immediate and constant. This showed in the final video product.

However, there is also limitation seeing from the result of students' project or Vlog production. It is discovered that there is unequal quantity of speaking roles. Some students had longer speaking roles while others had shorter roles, which meant that some students received more English practice than others. It might be caused by a reason where some students were quite anxious about performing in front of the camera. Despite this fact, it seems a reasonable rule to follow as in Video Blogging not all actors will be the star as long as they have portion to perform, it may direct to understanding that they have had a willingness to practice.

\section{CONCLUSION}

Vlogging is a good oral communicative application. This process is a trial and error method where students would learn from their errors with the help of a facilitator. Vlogging is part of instructional strategies which can be beneficial for ESP learning to create a project that relates with studying major. From the observation of the process before finishing Vlog, it can be summarized that the role of instructor is fully to facilitate students to learn and students are trained to improve their multiple skills, starting from the pre-preparation to sharing process.

Next, the questionnaire item stated that Vlog gave a chance for the respondents to learn on their cup of tea. The result showed that Vlog made respondents to enjoy learning English, and the instant feedback from teacher helped them to improve their speaking competency gradually. Thus, it can be concluded that Vlog are suitable to be implemented in ESP classroom as it might share a positive attitude for students' learning development and possibly to improve students' problem solving and collaboration skills in a fun learning atmosphere.

\section{References}

Anil, Beena.(2016). Top-up Students Second Language Talk Time through Vlogs.Indonesian Journal of EFL and Linguistics, Vol. I, No.2, 129-143

Carney, Nathaniel \& Foss, Patrick. (2008). Student-Produced Video: Two Approaches. Posted in English Teaching Forum, Volume 2.

Dabbagh, N., \&Bannan-Ritland, B. (2005).Online learning: Concepts, strategies, and application. Upper Saddle River: Pearson.

David, Gardner. (1994). Student Produced Video Documentary: Hongkong as a Self-Access Resource. 80(17), 45-53

Forester, Lee A. \& Meyer, E. (2015).Implementing Student-Produced Video Projects in Language Courses. Journals of American Association of Teachers of German, 48(2), 192-210

Hobbs, R. (1998).The seven great debates in the media literacy movement.The Journal of Communication, 48(1), 16-32.

Hofer, M., \& Swan, K. O. (2005).Digital moviemaking-the harmonization of technology, pedagogy and content. International Journal of Technology in Teaching and Learning, 1(2), 102-110.

Jonassen, D. H., Grabinger, R. S., \& Harris, N. D. (1991). Instructional strategies and tactics. Performance Improvement Quarterly, 3(2), 29-47.

Norton, P., \& Hathaway, D. (2010).Video production as an instructional strategy: Content Learning and teacher practice. Contemporary Issues in Technology and Teacher Education, 10(1), 145-166.

Sad, SuleymanNihat.(2008). Using Mobile Phone Technology in EFL classes.Posted in English Teaching Forum, Volume 4. 


\section{APPENDIX 1}

Fill in the below questionnaires to identify your attitudes toward the project-video task. You only need to choose between YES or NO for each statements below.

Name :

Major :

1. I feel more comfortable and relaxed while learning English through creating video YES/NO

2. The time passes quickly while learning English through recording video YES/NO

3. It is hard to learn English through video creation YES/NO

4. My confidence increases while learning English YES/NO

5. Project Video task is not effective to encourage me using English YES/NO

6. Project Video learning is more enjoyable and motivated than traditional classroom learning YES/NO

7. I can practice English communication more easily through creating video YES/NO

8. I have positive attitude towards creating video to learn English YES/NO

9. I observe better while learning English with project video YES/NO

10. After some time, learning English language through creating video might not turn out to be boring YES/NO 